\title{
Individual stripe regulatory elements in the Drosophila hairy promoter respond to maternal, gap, and pair-rule genes
}

\author{
Guy Riddihough and David Ish-Horowicz \\ Imperial Cancer Research Fund, Developmental Biology Unit, Department of Zoology, University of Oxford, Oxford OXl \\ 3PS, UK
}

\begin{abstract}
Striped expression of the pair-rule gene hairy (h) plays a central role in regulating segmentation in Drosophila. We have used $h-l a c Z$ reporter gene fusions to delineate $h$ sequences that drive individual stripe expression. We show that $14 \mathrm{~kb}$ of $5^{\prime}$-flanking DNA directs expression of seven $1 a c Z$ stripes in the blastoderm embryo. Within this region, we identify discrete sequences required for expression of individual stripes $1,5,6$, and 7 , and dispersed elements active in the stripe 2 domain. Only the stripe 1 element directs lacZ expression in an accurate $h$ stripe; stripes 5,6 , and 7 are displaced by one to two cells relative to their $h$ counterparts. These results indicate that regulatory sequences are dispersed within the $h$ promoter. We have determined the sensitivity of the lac $Z$ stripes to maternal, gap, and pair-rule gene mutations. Our results suggest that different but overlapping subsets of gap genes regulate each stripe and that activation and repression are both important in generating the stripe pattern.
\end{abstract}

[Key Words: Drosophila; hairy; segmentation; stripe elements; transcriptional regulation; pattern formation]

Received December 21, 1990; revised version accepted February 7, 1991.

Transcriptional regulation plays a pivotal role in the establishment of the Drosophila anteroposterior body plan. Segmentation is under the control of a hierarchy of segmentation genes (Nüsslein-Volhard and Wieschaus 1980; Nüsslein-Volhard et al. 1987), many of which encode transcription factors (for review, see Ingham 1988; Howard 1990). The precellular embryo is patterned by a transcriptional cascade in which initial maternal positional cues specifying terminal, anterior, and posterior regions of the embryo are refined through the action of zygotic gap and pair-rule segmentation genes. By the onset of gastrulation, when cellularization is complete, the embryo is subdivided into four-cell-wide parasegmental metameres, each bordered by one-cell-wide stripes of engrailed and wingless expression. Subsequent spatial patterning occurs within the parasegmental fields and requires cell-cell interactions and intracellular signaling.

The metameric organization of the embryo is first evident during the late blastoderm stage when the pair-rule genes are expressed in serially repeated stripes along the anteroposterior axis. Several lines of evidence suggest that the gap genes are largely responsible for the pair-rule striping pattern (for review, see Howard 1990; Pankratz and Jäckle 1990). Gap genes are expressed before the pairrule genes, and gap gene mutations cause localized disruption of pair-rule striping. The gap proteins are expressed in overlapping domains within which they lay down short-range morphogenetic gradients that regulate one another's domains and also cue pair-rule striping
(Pankratz et al. 1989; Stanojevic et al. 1989; Hülskamp et al. 1990). All of the characterized gap genes encode nuclear DNA-binding proteins, indicating that they regulate pair-rule transcription. The lack of cell membranes during the syncytial blastoderm stage allows transcription factors to regulate gene expression in adjacent nuclei directly.

In contrast, pair-rule RNAs and proteins appear coincident, perhaps due to the localization of pair-rule transcripts within a narrow strip of apical cytoplasm that restricts protein diffusion (Edgar et al. 1987; I. Davis and D. Ish-Horowicz, in prep.). The domains of different individual pair-rule gene stripes are staggered (phased) with respect to each other. hairy $(h)$ and even-skipped (eve) stripe domains are similar except that each $h$ stripe is displaced one to two cells anteriorly (Carroll et al. 1988b; Hooper et al. 1989; Kania et al. 1990). Such phasing of pair-rule domains is crucial in establishing metamerism as it leads to cells expressing the different combinations of pair-rule genes that establish precise domains of segment polarity gene expression and, hence, parasegments (Carroll et al. 1988a; Ingham et al. 1988).

There are two apparent mechanisms for achieving pair-rule striping. "Primary" genes ( $h$, runt, and eve) respond to gap gene cues and are largely responsible for patterning the "secondary" genes [e.g., fushi tarazu (ftz)]. The $h$ promoter includes extensive $(14 \mathrm{~kb})$ upstream sequence necessary for correct striping. The selective loss of these promoter sequences inactivates specific stripes, 
indicating that individual $h$ stripes are independently regulated, that is, different stripes respond to different positional cues (Howard et al. 1988; Hooper et al. 1989; Howard and Struhl 1990; Pankratz et al. 1990). Similarly, $8 \mathrm{~kb}$ of DNA upstream of the eve transcription unit drives reporter gene expression in only a subset of eve stripes (Goto et al. 1989; Harding et al. 1989). Gap gene protein-binding sites have been found in both the $h$ and eve promoters (Stanojevic et al. 1989; Pankratz et al. 1990). Thus, the information required to generate a reiterated pair-rule pattern is provided by earlier acting segmentation genes (gap and maternal genes), although it is unclear whether they directly specify more subtle phasing distinctions.

Striping of the secondary pair-rule genes is regulated predominantly by primary pair-rule genes. The striped pattern of $f t z$ expression appears to be due to repression by $h$ and eve such that toward the end of the blastoderm stage, $f t z$ expression domains correspond to the cells that express neither $h$ nor eve (Frasch and Levine 1987; Frasch et al. 1988; Hooper et al. 1989; Ish-Horowicz et al. 1989).

The apparent mechanistic distinction between primary and secondary pair-rule gene striping is also reflected at the molecular level. In contrast to the extensive promoters of the primary pair-rule genes (above), $f t z$ includes a small $\sim 600$-bp "zebra" regulatory element that suffices to drive seven-striped expression of an Escherichia coli $\beta$-galactosidase (lacZ) reporter gene (Hiromi et al. 1985; Hiromi and Gehring 1987; Dearolf et al. 1989).

As $h$ is a fundamental requirement for transducing asymmetric cues to metameric pattern, we have further investigated the mechanism of its striping. In this paper we show that various $h$ upstream regions drive regionalized expression of a lac $Z$ reporter gene in domains broadly corresponding to the $h$ stripes. These experiments show that the majority of $h$ stripes are independently regulated and must be responding to different spatial cues. Unexpectedly, only the stripe 1 reporter construct faithfully recreates the $h$ stripe boundaries. Other stripes show subtly displaced domains of lac $Z$ expression, indicative of missing regulatory signals in the fusion constructs and suggesting that $h$ "stripe elements" are less discrete than might have been envisaged previously. The effects of maternal, gap, and pair-rule gene mutations on $l a c Z$ reporter gene expression indicate that different but overlapping subsets of segmentation genes regulate the different pair-rule stripes. Depending on context, individual gap genes function phenotypically as both activators and repressors of the lacZ stripes. We discuss these results in terms of models for pair-rule gene activation and phasing.

\section{Results}

Upstream $\mathrm{h}$ sequences drive striped lac $\mathrm{Z}$ expression

The $h$ promoter extends $>14 \mathrm{~kb}$ upstream of the transcription start site (Howard et al. 1988; Rushlow et al.
1989|. cosh, a 28 -kb cosmid with $14 \mathrm{~kb}$ of upstream sequence, rescues segmentation in $h$ mutant embryos and expresses the full complement of seven blastoderm stripes and the anterodorsal (AD) head patch (M.T. Lardelli and D. Ish-Horowicz, in prep.). Sequences even farther upstream of cosh are required for the pupal $h$ activity that suppresses development of ectopic bristles (Howard et al. 1988; Rushlow et al. 1989).

Evidence for independent control of $h$ stripes comes from several chromosomal rearrangements yielding loss of specific $h$ stripes (Howard et al. 1988; Hooper et al. 1989) and has been extended via an ordered set of upstream deletions that cause progressive loss of $h$ stripes (M.T. Lardelli and D. Ish-Horowicz, in prep.). However, such studies cannot define stripe elements, which are minimal promoter regions sufficient to direct transcription in an individual stripe domain.

We have demonstrated such elements in the $h$ promoter by driving striped blastoderm expression of a suitable reporter gene. The vector, $p \beta n 27.1$, includes a truncated $h s p 27$ promoter fused to a $1 a c Z$ gene encoding a modified $\beta$-galactosidase protein that localizes to the cell nucleus (e.g., Fig. 2b, below; see Materials and methods and Fig. 8, below). The nuclear localization enhances the sensitivity of $l a c Z$ detection during the blastoderm stage, as well as mimicking the nuclear localization of $h$ protein (Carroll et al. 1988b; Hooper et al. 1989). Expression patterns from our constructs depend on the inserted $h$ sequences, although occasional transformant lines show later expression (mainly in the nervous system) that depends on the chromosomal integration site (not shown; see O'Kane and Gehring 1987).

Transformant $\beta h 14 \mathrm{~kb}$ (Fig. 1; for explanations of construct names, see legend), which includes the entire 14 $\mathrm{kb}$ of upstream $h$ DNA present in cosh, directs $1 a c Z$ expression in seven stripes resembling the endogenous $h$ stripes, although the AD domain is lacking and stripes 3 and 4 are weak (Fig. 2a). We examined the relative positioning of endogenous $h$ and reporter lac $Z$ stripes in more detail by immunohistochemical double staining with $h$ and $l a c Z$ antibodies. In general, the stripes correspond well, except for low-level lac $Z$ expression between $h$ stripes 5, 6, and 7 (interstripes 5/6 and 6/7; Fig. 2b). Weak expression is also occasionally seen among stripes 1,2 , and 3 (not shown). These results suggest that interstripe regulatory elements are partially disabled in the $\beta h 14 k b$ construct (see Discussion).

$\beta h 7 \mathrm{~kb}$, which represents the distal (upstream) half of $\beta h 14 k b(-14$ to $-6.8 \mathrm{~kb}$; Fig. 1), directs expression in domains that approximate to stripes 6 and 7 and weakly between them (Fig. 2c). They resemble authentic $h$ stripes, but double labeling with $h$ protein shows that these stripes are displaced posteriorly, coincident with eve stripes 6 and 7 (Figs. 2d and 51,m; see below). For the rest of this paper, we use a "prime" designation (e.g., 6" and $7^{\prime} \mid$ to distinguish between accurate and imprecise stripe domains. $\beta h 7 \mathrm{~kb}$ also expresses $1 a c Z$ transcripts in very weak stripes, $2^{\prime}, 3^{\prime}$, and $4^{\prime}$ (Fig. $2 c$; see Materials and methods). These stripes are not detected at blastoderm with our lacZ antibody but are seen at full germ-band 


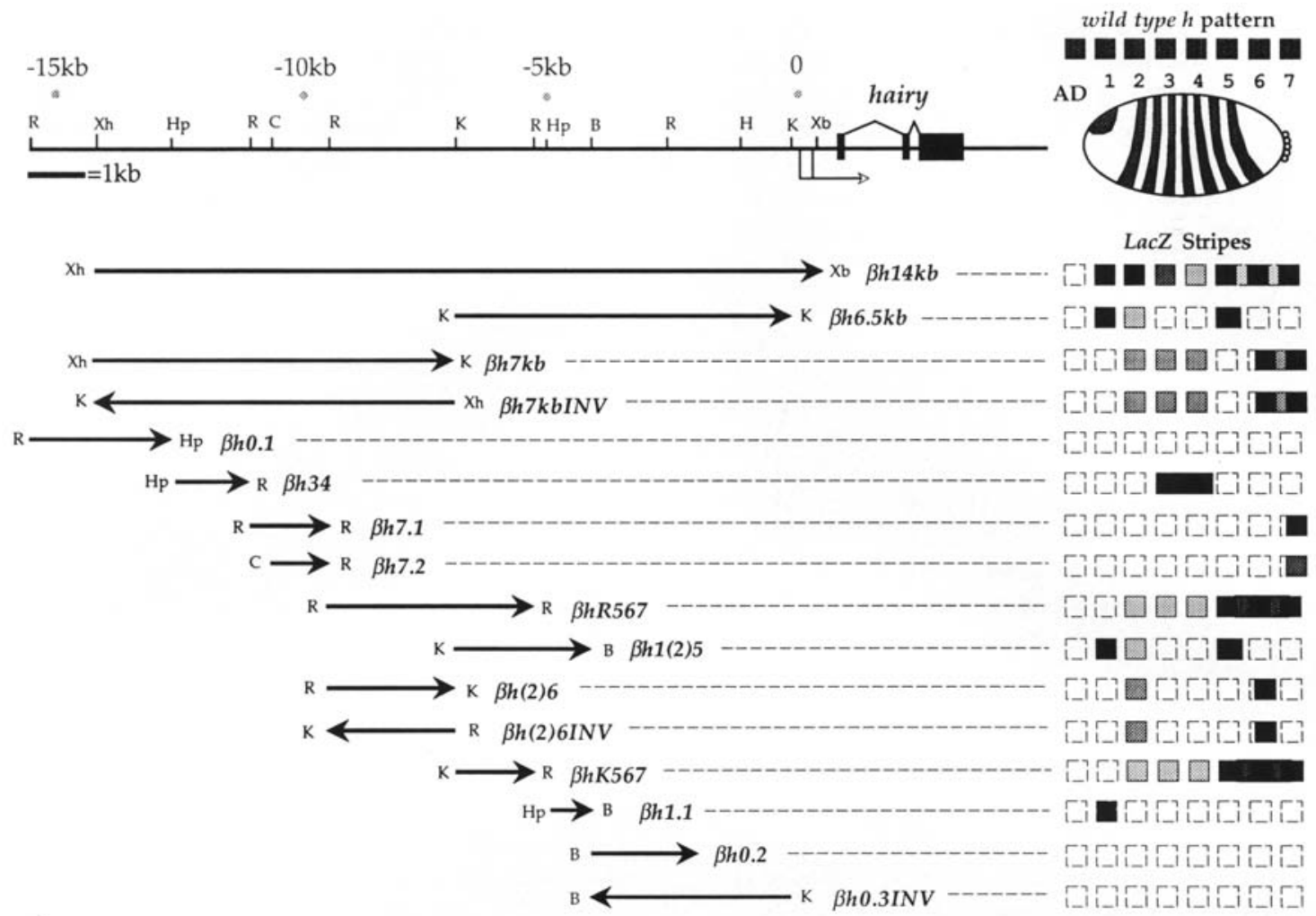

Figure 1. Diagram of the $h$ promoter fragments used in $l a c Z$ fusions and their blastoderm stripe patterns. (Top) A partial restriction map of $\sim 15 \mathrm{~kb}$ of sequences flanking the $h$ gene. The $h$-coding sequences are shown as solid boxes linked by introns. The start points of the two $h$ transcripts are indicated by the open arrow, the upstream one representing $0 \mathrm{~kb}$ on the map (Ish-Horowicz et al. 1985). (Below) The filled arrows correspond to the 5' DNA fragments fused to lacZ in $p \beta n 27.1$ (Fig. 8). Rightward arrows are in the correct orientation relative to the $h s p 27$ TATA box; leftward arrows are inverted. Restriction sites used to isolate the fragments are indicated. The names of the transformant lines are shown adjacent to the arrows; the top three fragments are identified by their size; the remainder are indicated by the stripes they generate, e.g., $\beta h(2) 6$ produces a weak stripe $2^{\prime}$ and a strong stripe $6^{\prime}$. The $1 a c Z$ stripes generated are shown at right as stippled or solid; the darkness reflects the strength of lac $Z$ expression at the blastoderm stage. Interstripe and shifted stripe domains are also indicated. Restriction enzyme sites are (B) BamHI; $(\mathrm{H})$ HindIII; $(\mathrm{Hp}) \mathrm{HpaI}$; (K) KpnI; $(\mathrm{N})$ NotI; (Nc) NcoI; (R) EcoRI; (S) SalI; (Sb) SnaBI; (Sc) SacI; (Xb) XbaI; and (Xh) XhoI.

extension when presumably the lac $Z$ antigen has accumulated to a detectable level (data not shown). Although unable to drive bona fide stripes 2,3 , and $4, \beta h 7 \mathrm{~kb}$ includes sequences that can contribute to their regulation. Inversion of this fragment $(\beta 7 \mathrm{kbINV}$; Fig. 1$)$ has no effect on the pattern of stripes generated (not shown).

The proximal $6.5-\mathrm{kb}$ fragment $(\beta h 6.5 \mathrm{~kb} ;-6.8$ to -0.3 $\mathrm{kb})$ and a subfragment $(\beta h 1(2) 5 ;-6.8$ to $-4 \mathrm{~kb})$ generates two strong stripes, 1 and $5^{\prime}$, and a very weak stripe, 2 ' (Fig. 2e,f). Thus, the stripes generated by the two promoter halves, $\beta h 6.5 \mathrm{k} b$ and $\beta h 7 \mathrm{~kb}$, together yield the whole pattern of the $\beta h 14 \mathrm{~kb}$ fragment except for a much weaker stripe 2 (see below). Sequences between $-4 \mathrm{~kb}$ and -173 bp appear unable to drive lac $Z$ expression $(\beta h 0.2$ and $\beta h 0.3 I N V$; Fig. 1), and their removal from $\beta h 6.5 \mathrm{~kb}$ leaves stripes $1,2^{\prime}$, and 5' unaffected [construct $\beta h 1(2) 5$; Fig. 2e]. Mutant $h$ genes that retain $3.4 \mathrm{~kb}$ or less of upstream DNA are similarly inactive (M.T. Lardelli and D. Ish-Horowicz, in prep.).

We now consider each $h$ stripe in turn. Our results are generally consistent with similar studies by Howard and
Struhl (1990), Pankratz et al. (1990), and M.T. Lardelli and D. Ish-Horowicz (in prep.). We mention their results where they extend or conflict with our own.

\section{The AD domain (stripe 0)}

None of our $l a c Z$ reporter constructs direct expression in the $\mathrm{AD}$ domain (Fig. 2). It appears that $\mathrm{AD}$ expression requires sequences 3 ' to the $h$ transcription unit, none of which are present in our constructs (M.T. Lardelli and D. Ish-Horowicz, in prep.).

\section{Stripe 1}

A 900 -bp fragment $(\beta h 1.1 ;-4.9$ to $-4 \mathrm{~kb})$ suffices to drive lac $Z$ expression in an accurate stripe 1 domain (Fig. $2 \mathrm{~g}-\mathrm{i})$. This stripe element functions in either orientation because it is still active when inverted in an $h$ promoter construct (M.T. Lardelli and D. Ish-Horowicz, in prep.).

We tested the dependence of stripe 1 expression on maternal and zygotic gene expression affecting anterior 
and terminal pattern (Figs. 3 and 4). As expected from their deleted anterior fate map (Frohnhöfer and Nüsslein-Volhard 1986), bicoid nanos (bcd nos) embryos (embryos derived from $b c d$ nos mothers) lack stripe 1 (Fig. 4; the nos mutation does not affect stripe 1). In vasa exuperentia (vas exu) embryos, bcd is expressed at a low level in a very shallow gradient (Struhl et al. 1989). These embryos retain an anteriorly shifted stripe 1 and a faint duplicated posterior stripe 1 (Fig. 3a), whereas stripe 1 is lacking in staufen exu (stau exu) embryos (results summarized in Fig. 4; see Discussion). These results indicate that stripe 1 is under $b c d$ control.

Stripe 1 is expanded anteriorly in torso (tor) embryos, suggesting that its anterior edge is defined by the terminal gene system (Fig. 3b). However, no individual zygotic gap gene eliminates stripe 1 , which is retained in embryos mutant for hunchback (hb) (not shown), Krüppel $(\mathrm{Kr})$, giant (gt), or knirps (kni) (Fig. 5d-f) and in embryos mutant for the gnathal gap genes orthodenticle (otd), empty spiracles (ems), and buttonhead (btd) (not shown).

$h$ stripe 1 is also subject to dorsoventral regulation, being repressed in the ventral $10 \%$ of the stripe (Hooper et al. 1989). Construct $\beta$ h1.1 retains dorsoventral regulation, lacking ventral lac $Z$ expression (Fig. 2i), which is restored in dorsal and twist mutant embryos (not shown). The sequences mediating ventral repression of this stripe must lie between -4.9 and $-4 \mathrm{~kb}$ and may include sites that respond directly to twist protein (Thisse et al. 1988).

\section{Stripe 2}

Several lines of evidence suggest that elements responsible for stripe 2 expression are dispersed throughout at least $5.4 \mathrm{~kb}(-9.4$ to $-4 \mathrm{~kb})$. First, $\beta h 14 \mathrm{~kb}$ expresses stripe 2 at normal levels, but individual subfragments, $\beta h 7 k b$ (Fig. 2c), $\beta h 6.5 \mathrm{~kb}$ (not shown), $\beta h 1$ (2) 5 (Fig. 2e), $\beta h R 567$ (not shown), $\beta h(2) 6$ (Fig. 2n), and $\beta h K 567$ (Fig. $2 \mathrm{k}$ ) drive weak stripe 2 expression. Second, $h$ promoter deletions broken between -8.3 and $-5.6 \mathrm{~kb}$ reduce, but do not eliminate, stripe 2 expression (Howard et al. 1988; M.T. Lardelli and D. Ish-Horowicz, in prep.). Unlike Howard and Struhl (1990), we do not see strong stripe 2 expression with an inverted construct [ $(\beta h(2) 6 I N V$; not shown), but this may reflect differences in our plasmid constructs.

\section{Stripes 3 and 4}

Sequences outside of the 14-kb promoter fragment are needed for authentic expression of stripes 3 and 4 /Fig. 2a). Even within the 14-kb fragment, elements for stripes 3 and 4 are scattered over large distances. Expression in these stripes is seen in $\beta h 7 k b$ (very weak; -14 to -6.4 kb; Fig. 2c), $\beta h R 567$ (not shown), and $\beta$ hK567 (very weak; -6.4 to $-5.2 \mathrm{~kb}$; Fig. 2 j). Although we have not yet isolated elements that direct accurate expression in individual stripe 3 and 4 domains, construct $\beta h 34$ $(-12.4$ and $-11 \mathrm{~kb}$; Fig. 1) drives $1 a c Z$ expression in a broad central domain (stripe $3^{\prime}-4^{\prime}$ ), roughly from $h$ stripe 3 to interstripe $4 / 5$ (Fig. $2 \mathrm{~m}$ ).

Ectopic expression between domains 3 and 4 is associated with the lack of downstream sequences, -11 to $-10.6 \mathrm{~kb}$, that repress interstripe expression (ET22, Howard and Struhl 1990; hCC-lacZ, Pankratz et al. 1990). We do not see the domain resolving into stripes 3 and 4 in later embryos (Howard and Struhl 1990), but this may result from our slightly differing constructs. Like Howard and Struhl (1990), we do not detect blastoderm expression driven by sequences between -15 and $-12.4 \mathrm{~kb}$ (transformant $\beta$ h0.1).

$h$ stripes 3 and 4 lie in the middle of the $K r$ domain, suggesting that they are activated by $K r$. Stripe $3^{\prime}-4^{\prime}$ expression is much thinner but not abolished in $\mathrm{Kr}$ mutant embryos, suggesting that $K r$ is not the sole activator of this domain. It is broadened in kni embryos, where the $\mathrm{Kr}$ domain is expanded (Fig. 5a,b; Gaul et al. 1987), and unaffected in $h b$ or $g t$ embryos (not shown). Stripe $3^{\prime}-4^{\prime}$ follows $K r$ expression in maternal mutations that perturb gap gene domains. It is abolished in vas exu embryos that do not express $K r$ (Fig. 4; Gaul and Jäckle 1989) and broadened in oskar (osk) and bcd nos embryos (Fig. 3c,d), in which $\mathrm{Kr}$ expression is expanded (Gaul and Jäckle 1989). The latter show that maternal $h b$ expression is insufficient to repress stripe $3^{\prime}-4^{\prime}$. In stau exu embryos that express high levels of both $h b$ and $K r$ /Gaul and Jäckle 1989), $\beta$ h34 no longer encodes a lacZ stripe but, instead, drives expression ventrally (Fig. 3e), most strongly at the onset of gastrulation (not shown). Strikingly, this correlates with the intense ventral $K r$ expression during gastrulation (Fig. 2I in Gaul and Jäckle 1989), consistent with $\mathrm{Kr}$ playing an activating role and suggesting that high levels of $h b$ may repress expression.

\section{Stripe 5}

Stripe 5 is largely encoded by sequences between -6.8 and $-4 \mathrm{~kb}$. Transformants $\beta h 6.5 \mathrm{~kb}(-6.8$ to $-0.3 \mathrm{~kb})$ and $\beta h 1(2) 5(-6.8$ to $-4 \mathrm{~kb})$ express stripe 1 , a very weak stripe $2^{\prime}$, and a slightly wider stripe $5^{\prime}$ (Fig. 2e,f). By the end of blastoderm, the anterior $5^{\prime}$ boundary is accurate, but the ventral posterior boundary is extended by about one cell (Fig. 2f). Removing an additional $1.2 \mathrm{~kb}$ from $\beta h 1$ (2) 5 (construct $\beta h K 567$; -6.8 to $-5.2 \mathrm{~kb}$ ) causes loss of stripe 1 and a much broader stripe 5 whose posterior boundary extends to that of $h$ stripe 7 (band 5-6-7; Fig. 21). Additional upstream sequences ( $\beta h R 567$; not shown) do not alter the 5-6-7 domain (not shown).

The upstream $h$ region in $\beta h K 567$ drives striped expression in domains whose major elements are encoded elsewhere. $1 a c Z$ expression within the 5-6-7 band is not uniform and includes two strong stripes; the broad anterior stripe lies anterior to and includes stripe 6 while the second approximates to stripe 7 (Fig. 2k). Anterior 5-6-7 expression resembles stripe 5 and 6 , being lost in kni embryos (Fig. 5c). However, posterior expression in the 5-6-7 domain is distinct from the authentic $h$ stripe $7 . h$ stripe 7 expression is retained and expanded in osk embryos (Fig. 3j; Hooper et al. 1989), whereas the 5-6-7 


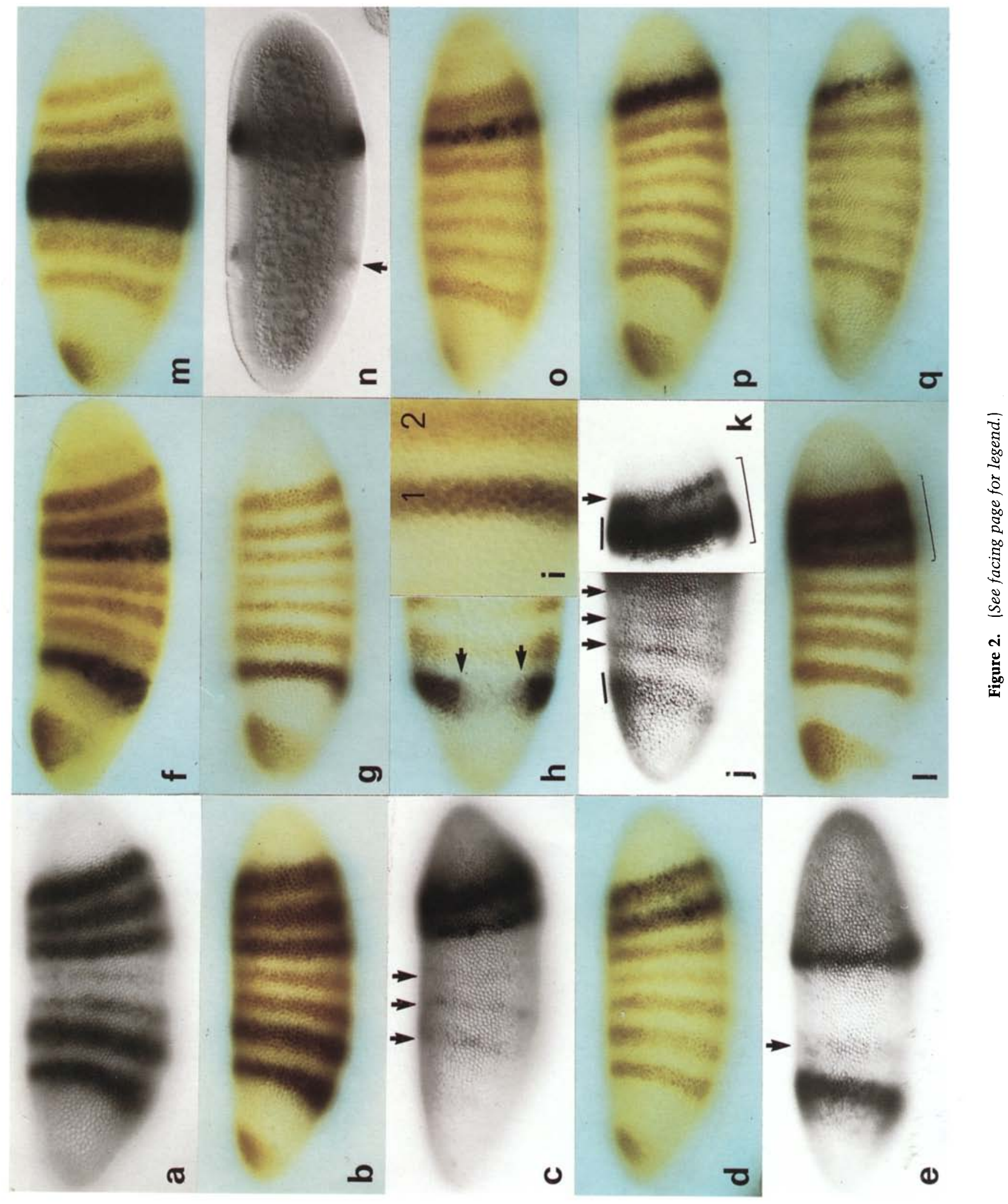


domain is lost (Fig. 4). Band 5-6-7 and $7^{\prime}$ are also affected differently in tor embryos (Fig. 3f,k). Also, stripes $6^{\prime}$ and $7^{\prime}$ appear to be largely encoded by upstream DNA (see below).

$\beta h K 567$ also directs weak expression in the acron and in three thin anterior stripes, $2^{\prime}, 3^{\prime}$, and $4^{\prime}$ (Fig. $2 \mathrm{j}$ ), which are also seen in $\beta h 7 k b$ (Fig. 2c). The broad acron "stripe" lies just anterior to $h$ stripe 1 (see Materials and methods).

Although our stripe $5^{\prime}$ constructs also express stripe 1 , they allow us to show that stripe $5^{\prime}$ is affected by the gap genes $K r$ and $k n i$, which behave as activators, and $g t$, which acts as a repressor. $5^{\prime}$ expression is lost in $\mathrm{Kr}$ and osk embryos (Figs. $5 \mathrm{~d}$ and $3 \mathrm{~g}$, respectively) and considerably narrowed in kni embryos (Fig. 5f). Conversely, the stripe expands posteriorly in $g t$ embryos, suggesting that $g t$ repression may define its posterior edge (Fig. 5e). We cannot yet ascertain which gene(s) establish this anterior stripe margin as it is not affected by any mutations tested.

\section{Stripe 6}

Sequences between -9.1 and $-5.2 \mathrm{~kb}$ direct expression in stripe $6^{\prime}$ and weakly in stripe 2 [in both orientations, constructs $\beta h(2) 6$ (Fig. $2 n, o$ ) and $\beta h(2) 6 I N V$ (not shown)]. Double staining of $\beta h 7 \mathrm{~kb}$ and $\beta h(2) 6$ embryos shows that the $1 a c Z$ domain lies about one cell posterior to $h$ stripe 6 (Fig. 2d,o). This slight stripe displacement could be due either to missing gap gene regulatory elements or to lack of "phasing" elements that refine final stripe domains (see Discussion).

Stripe $6^{\prime}$ is patchy, with individual cells within the stripe stochastically initiating lac $Z$ expression until most cells within the stripe express $l a c Z$ at varying levels (Fig. 2o). This distinction between cells is not due to threshold differences in gap protein concentrations because it is unaffected by gap gene dosage. We analyzed embryos heterozygous for $K r$ and kni mutations and found no difference in $l a c Z$ staining in such embryos (not shown), suggesting that the indeterminacy of staining is due to limiting concentrations of other transcriptional components.

Pankratz et al. (1990) have suggested that stripe 6 is defined by $\mathrm{Kr}$ and $\mathrm{kni}$. Although our results are consistent with this view, we show that the stripe depends on additional spatial cues. Stripe $6^{\prime}$ is expanded anteriorly in $\mathrm{Kr}$ embryos, consistent with $\mathrm{Kr}$ repression defining the anterior boundary of stripe 6 (Fig. $5 \mathrm{~g}$; Pankratz et al. 1990). In tor embryos, stripe $6^{\prime}$ is expanded posteriorly (Fig. $3 \mathrm{~h}$ ), suggesting that the terminal gap genes are involved in defining the posterior boundary of the stripe, one of which is probably tailless (t11), as $6^{\prime}$ is similarly expanded in tll embryos (Fig. 5h). Stripe $6^{\prime}$ is lost in both gt and kni (not shown), suggesting that they behave as local activators of the $h$ gene.

\section{Stripe 7}

Construct $\beta h 7.1(-11$ to $-9.4 \mathrm{~kb})$ expresses $1 a c Z$ in stripe $7^{\prime}$, which is shifted one to two cells posterior to $h$ stripe 7 (Figs. $2 p$ and 51), like the stripe in $\beta h 7 k b$ (Fig. 2d). Sequences between -10.6 and $-9.4 \mathrm{~kb},(\beta h 7.2)$ are sufficient for weak expression of the stripe, although it remains posteriorly shifted (Fig. 2q). Howard and Struhl (1990) detect no expression using an identical fragment, which suggests that our use of a nuclear lacZ protein indeed enhances sensitivity. Initiation of this weaker stripe $7^{\prime}$ is irregular, like stripe $6^{\prime}$ (construct $\beta h(2) 6$; Fig. 2o).

Stripe $7^{\prime}$ depends on the terminal and posterior genes. It is present and duplicated in $b c d$ nos embryos that retain only the terminal coordinate system (Fig. 3i). The stripe is completely abolished in tll embryos (not shown) but not tor embryos, which retain staining at the very posterior tip of the embryo (Fig. 3k). tor embryos may lack a repressor that expands in $t 11$ embryos. Stripe $7^{\prime}$ is broader in osk, bcd nos, and kni mutant embryos (Figs.

Figure 2. lac $Z$ striping patterns generated by $h$ promoter fragments at the blastoderm stage. lac $Z$ transcript patterns or embryos double-stained for $h$ (brown) and $l a c Z$ (dark blue) proteins are shown. $(a)$ | $h 14 \mathrm{~kb}$ embryos showing seven stripes of $l a c Z$ RNA expression that resemble the $h$ pattern except for weaker stripes 3 and 4 and lack of the AD domain. $(b)$ Antibody double staining of $\beta h 14 \mathrm{~kb}$ embryos shows that the lac $Z$ protein is nuclear and that the $h$ and $l a c Z$ stripes are coincident. Ectopic lac $Z$ expression is seen among stripes 5-6-7. (c) $\beta h 7 \mathrm{~kb}$ lac Z RNA is expressed in two strong posterior stripes, $6^{\prime}$ and $7^{\prime}$, with low levels of expression between these stripes, and in weak stripes $2^{\prime}, 3^{\prime}$, and $4^{\prime}$ (arrows). (d) Antibody double staining of $\beta h 7 k b$ does not reveal the weak RNA stripes at this stage but shows that $6^{\prime}$ and $7^{\prime}$ are shifted posteriorly with $6^{\prime} / 7^{\prime}$ interstripe expression. (e) Extensive staining for $\beta h 1(2) 5$ lac $Z$ RNA reveals strong stripes 1 and $5^{\prime}$ and weak stripe $2^{\prime}$ expression (arrow). The weak posterior staining in this embryo is not typical of such embryos. $(f)$ Antibody double staining shows that stripe 1 is accurate, whereas the posterior boundary of $5^{\prime}$ is shifted posteriorly in $\beta h 6.5 \mathrm{~kb}$ [and $\beta h 1(2) 5$; not shown] embryos. Stripe 2 ' expression is not seen at this stage. (g-i) $\beta h 1.1$ transformants direct expression of $l a c Z$ protein in stripe 1 , which shows the ventral gap (arrows) and is cell for cell the same as the endogenous stripe ( $h$ stripes 1 and 2). ( $j$ and $k$ ) $\beta h K 567$ (and $\beta h R 567$; not shown) shows weak lacZ RNA expression in stripes $2^{\prime}, 3^{\prime}$, and 4' (arrows), anterior of $h$ stripe 1 (line), and strong expression in a complex domain (bracket) that spans $h$ stripes 5-6-7 (two exposures of the same embryo). The broad $6^{\prime}$-like stripe is indicated with a line, and $7^{\prime}$ with an arrow. The corresponding protein expression is seen in 1 ( $\left.\beta h K 567\right)$ and spans $h$ stripes 5-6-7 (bracket). $(\mathrm{m}) \beta h 34$ drives lac $Z$ protein expression in a domain that spans $h$ stripe 3 and extends beyond stripe 4 . (n) Single antibody staining of $\beta h(2) 6$ for lacZ protein reveals stripe $6^{\prime}$ and faint stripe $2^{\prime}$ expression (arrow) in an embryo that has just started to gastrulate (note cephalic furrow anterior to stripe $\left.2^{\prime}\right)$. (o) Antibody double staining of $\beta h(2) 6$ reveals that stripe $6^{\prime}$ is posteriorly displaced. A similar shift is seen with the stripe $7^{\prime} l a c Z$ protein expression driven by $\beta h 7.1\langle p)$ and by $\beta h 7.2\langle q|$, with the latter being expressed more weakly. Embryos are visualized under Nomarski illumination and are oriented so that anterior is to the left and dorsal is up unless stated otherwise (also in Figs. 3-8). 


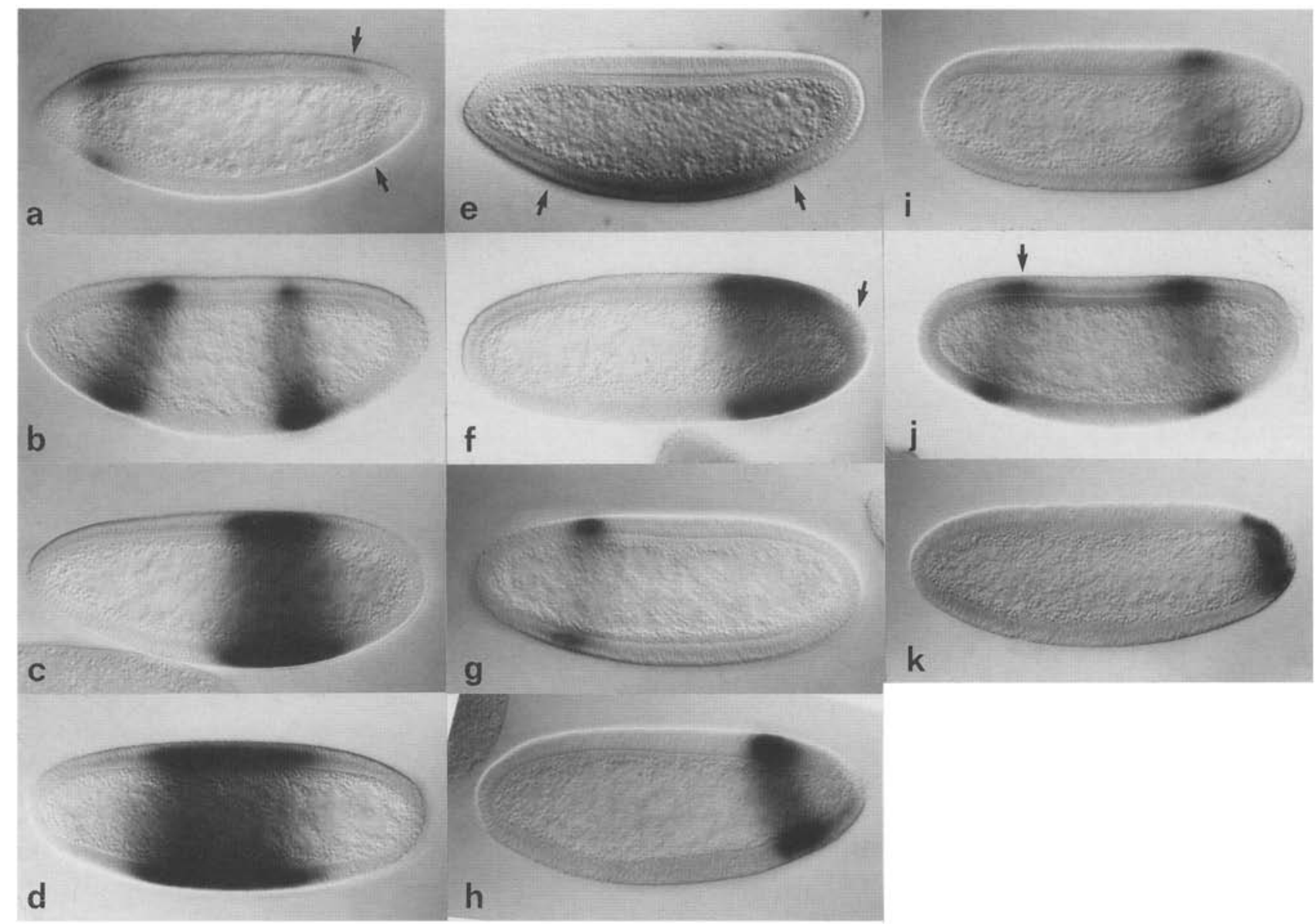

Figure 3. lac $Z$ stripe expression in maternal mutations that define anterior, posterior and terminal domains of the embryo (see also Fig. 4). (a) Bh1.1 expression in embryos from homozygous vas exu mothers. Stripe 1 is shifted toward the anterior, and there is a faint posterior duplication of the stripe (arrows). (b) $\beta h 6.5 \mathrm{~kb}$ in tor embryos; stripe 1 is expanded considerably toward the anterior, whereas $5^{\prime}$ is slightly posteriorly expanded. (c) $\beta h 34$ expression in osk embryos; the domain expands posteriorly. (d) $\beta h 34$ in bcd nos doublemutant embryos; the domain expands both toward the anterior and the posterior. (e) $\beta h 34$ expression in stau exu embryos; expression is only seen ventrally (between arrows), which becomes much stronger as gastrulation proceeds (not shown). $(f) \beta h R 567$ expression in tor embryos; the domain expands toward the posterior pole, where its expression is either low or absent (arrow) [cf. $7^{\prime}$ in tor $\left.(k)\right]$. $(g)$ $\beta h 6.5 \mathrm{~kb}$ expression in osk embryos; stripe 1 is unaffected, but stripe $5^{\prime}$ is lost. $(h) \beta h(2) 6$ expression in tor embryos; stripe $6^{\prime}$ expands and shifts toward the posterior pole. (i) $\beta h 7.1$ expression in osk embryos; the stripe $7^{\prime}$ domain is expanded toward the anterior. $(j) \beta h 7.1$ expression in $b c d$ nos embryos; the stripe $7^{\prime}$ domain is expanded as in $i$ and shows a mirror-image duplication in the anterior of the embryo (arrow). $(k) \beta h 7.1$ expression in tor embryos; the stripe $7^{\prime}$ domain is reduced, and intense staining is seen at the very posterior pole of the embryo although not in the pole cells.

$3 i, j$ and $5 i$, suggesting that kni may help define the anterior border. Expression is unaffected by the absence of gt (not shown).

The stripe is normal in huckebein (hkb) embryos, implying that other terminal gene(s) are involved in defining its posterior border. $h k b$ and forkhead appear to pattern $f t z$ stripe 7 (Casanova 1990) redundantly, suggesting that they may act similarly on $h$ stripe $7^{\prime}$.

\section{Stripe elements and pair-rule phasing}

The posterior borders of $l a c Z$ stripes $5^{\prime}, 6^{\prime}$, and $7^{\prime}$ are displaced posteriorly in most of our constructs. Either the constructs are incorrectly regulated or the relatively stable lacZ protein might not mimic the rapid dynamics of $h$ patterning. We disproved the latter idea by examining lacZ striping from an "enhancer trap" inserted into the $h$ gene. $P(l a c, r y) h^{L 43 a}$ is inserted near the $h$ transcription initiation site and expresses $l a c Z$ in a $h$ striped pattern (Fasano et al. 1988; M.T. Lardelli and D. IshHorowicz, in prep.). Double staining for $h$ and $l a c Z$ shows that the two sets of stripes are expressed in the same cells (Fig. 5i), suggesting that the phase shifting of our reporter gene stripes is due to their misregulation and not to differences in mRNA or protein stability.

Cross-regulatory interactions between the primary pair-rule genes suggest that they also participate in generating stripes (Ingham and Gergen 1988). We have ex- 


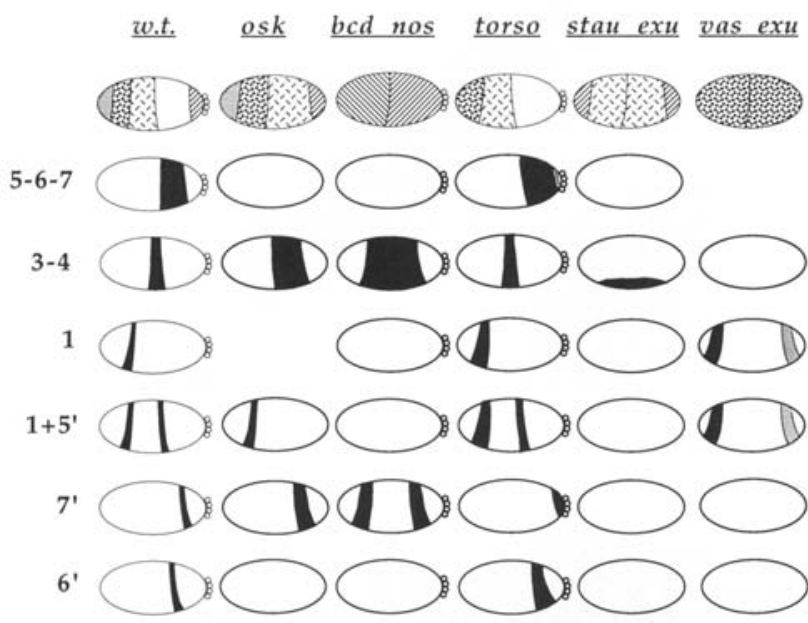

Figure 4. Summary of $l a c Z$ expression in maternally affected embryos, i.e., derived from mothers with mutations in maternal coordinate segmentation genes. (Top left) Embryo represents a wild-type fate map; the acron (light stippling), the head (dark stippling), the thorax (dashes), the abdomen (open), and the telson (hatching). The rest of the top row shows the altered fate map in the various mutant backgrounds; the rows below this represent the different $l a c Z$ stripes $(5-6-7=\beta h R 567 / \beta h K 567$; $3^{\prime}-4^{\prime}=\beta h 34$, etc.). Domains of strong expression are shown in black, weaker domains are shaded, and blank ovals represent no lac $Z$ expression at the blastoderm stage. Examples of some of the expression patterns are shown in Fig. 3 .

amined expression of several of our constructs in pairrule mutant embryos and find general concordance between the mutant patterns of $h$ and lac $Z$ expression. lacZ expression from $\beta h 14 \mathrm{~kb}$ is unaltered in an $\mathrm{h} \mathrm{mu}$ tant background (not shown), confirming previous evidence that $h$ is not autoregulated (Hooper et al. 1989). In runt (run) embryos, stripe 1 is broadened, stripe $5^{\prime}$ thinner (Fig. 5k), stripe $6^{\prime}$ is expanded (Fig. 5o), and stripe $7^{\prime}$ is unaffected, consistent with the effects on $h$ protein staining (Carroll and Vavra 1989; Hooper et al. 1989). Although stripes $6^{\prime}$ and $7^{\prime}$ resemble eve stripes 6 and 7 , they are unaltered in eve embryos $\left(7^{\prime}\right.$, Fig. 51-n; $6^{\prime}$, not shown), suggesting that the similarity is not significant. These results indicate that pair-rule cross regulation acts more to refine pair-rule expression domains than to establish their initial stripes.

\section{Discussion}

Our results indicate that $h$ striping is controlled transcriptionally and that individual stripes are independently regulated consistent with the role of $h$ as a primary pair-rule gene. We show that for the majority of the isolated stripe domains either one or both borders of the stripes are subtly displaced relative to their endogenous $h$ counterparts. We also find minor stripe elements scattered within the promoter. Both of these results suggest that at least some of the stripe elements are not necessarily discrete.

Our results suggest that striping of primary pair-rule genes is largely mediated by differing concentrations and combinations of gap gene proteins that activate expression within stripes and repress expression in interstripes (Lehmann and Frohnhöfer 1989; Stanojevic et al. 1989; Struhl 1989; Pankratz and Jäckle 1990; Pankratz et al. 1990). The majority of stripes tested depend on at least two gap genes, stripes $5^{\prime}$ and $6^{\prime}$ are affected by three different gap gene mutant backgrounds, and individual gap genes behave as activators for one stripe and as repressors for another. We also find that the primary pairrule gene run acts independently on various stripe elements.

\section{Are there discrete stripe elements?}

Although individual $h$ stripes respond to independent positional cues, such stripe elements do not appear simple or necessarily "discrete." With the exception of stripe 1, regions of upstream sequence drive subtly displaced lacZ stripes compared to their $h$ counterparts (Figs. 1 and 2). The clearest examples of displaced lacZ reporter stripes are stripes $6^{\prime}$ and $7^{\prime}$, which lie about one cell posterior to the normal $h$ domains. For several reasons, we consider it unlikely that these displaced stripe domains are due to reporter gene artifacts. First, the lacZ protein used is nuclear, like $h$ protein itself. Second, the full-length construct $\beta h 14 k b$ encodes authentic stripes (Fig. 2a). Third, several constructs encode an authentic stripe 1 , although other stripes are affected. Finally, the enhancer trap transposon $P\left(l a c, r y^{+}\right) h^{L 43 a}$ expresses a nuclear $l a c Z$ protein in authentic $h$ domains. This last construct also shows that accurate $h$ stripes do not depend on the localization of transcripts within the apical cytoplasm, a feature shown by all characterized pair-rule genes, because transcripts from both $p \beta n 27.1$ and the $P\left(l a c, r y^{+}\right) h^{L 43 a}$ are unlocalized (I. Davis and D. IshHorowicz, in prep.).

Lack of $l a c Z$ stripe precision could be due to deletion of gap gene-binding sites, as is undoubtedly the case for the severely misregulated stripe domains like 5-6-7 in BhK567 (Fig. 21). Sharp activation thresholds appear to require multiple interacting DNA-binding sites as demonstrated for the bcd morphogen (Driever et al. 1989; Struhl et al. 1989) and other transcription factors (Topol et al. 1985; Jaynes and O'Farrell 1988; Schüle et al. 1988). $h$ and $e v e$ stripe elements include multiple binding sites for gap gene proteins that may yield sharp stripe boundaries (Stanojevic et al. 1989; Pankratz et al. 1990). Partial deletion of such sites would displace stripe boundaries by affecting threshold response levels. For example, lacZ stripe $5^{\prime}$ has a shifted posterior boundary, whereas the anterior edge is faithfully maintained. This shift partially mimics the posterior shift seen in gt embryos, suggesting that some of the $g t$ response elements may have been lost.

However, the shifts of stripes $6^{\prime}$ and $7^{\prime}$ in construct $p \beta h 7 k b$ affect four adjacent stripe boundaries, inconsistent with a loss of gap gene-binding sites, which should affect different boundaries differently, that is, alter stripe widths. More likely, these stripes are displaced due to 


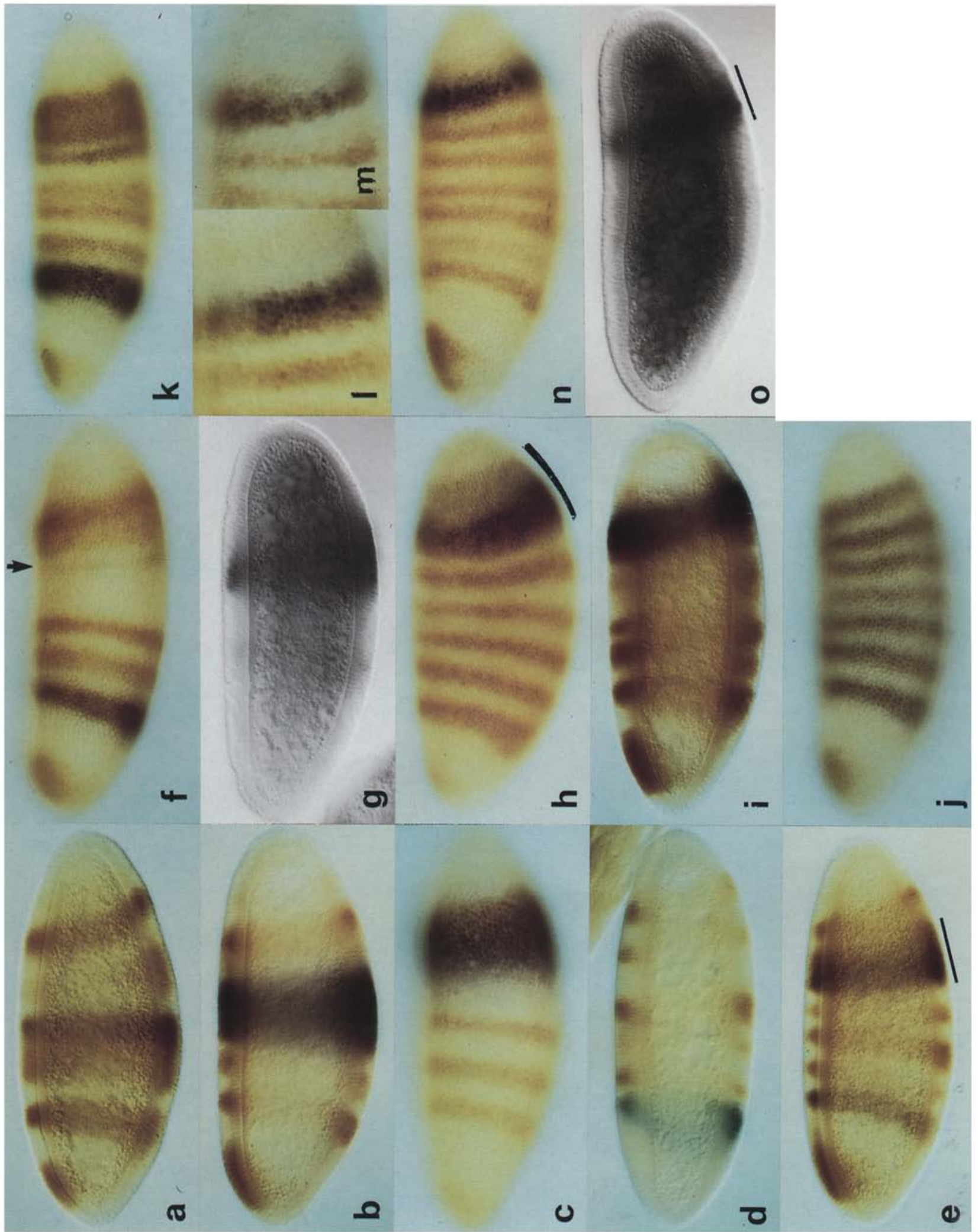

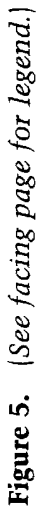


Regulation of $h$ stripe elements

lack of pair-rule elements that function to refine stripe phasing (see below).

A number of distinct fragments generate weak but correctly positioned $h$ stripes. Construct $\beta h K 567$ drives weak expression in stripes 3 and 4 for which a major transcriptional element can be mapped elsewhere, indicating that positionally responsive regulatory elements are dispersed within the promoter. Similar weak stripe elements are revealed by certain $h$ promoter deletions (M.T. Lardelli and D. Ish-Horowicz, in prep.). Although the stripes are thinner than their normal $h$ counterparts, their positions correspond to normal $h$ domains, an unlikely outcome if the regulation were accidental. Rather, the same regulators are driving both strong and weak stripes.

If these minor elements are not evolutionary relics, their function may be to contribute to stripe activation. Major stripe elements have to activate transcription over considerable distances (10 kb; Fig. 6) and can do so independent of orientation (Howard and Struhl 1990; M.T. Lardelli and D. Ish-Horowicz, in prep.). Perhaps major stripe elements require minor elements for locating the start of transcription within the extensive endogenous promoter but can activate the adjacent $h s p 27$ promoter in $p \beta n 27.1$ unaided. Such a model could explain why the sequences in $\beta h 34$ express stripe $3^{\prime}-4^{\prime}$ strongly but are only weakly active when displaced distally in $\beta h 7 k b$.

Several fragments of DNA regulate the expression of two or more domains, suggesting the interdigitation of control elements. Stripe 2 regulatory sequences extend over $\sim 5.4 \mathrm{~kb}$ and overlap those of stripes 1,5 , and 6 (Howard and Struhl 1990; M.T. Lardelli and D. IshHorowicz, in prep.). Removal of the sequences that direct stripe 1 expression deregulates the posterior boundary of stripe $5^{\prime}$, indicating that the region between -5.2 and $-4 \mathrm{~kb}$ contains repressing elements for the posterior boundary of stripe $5^{\prime}$ and activating elements for stripe 1 , and cryptic activator elements for $6^{\prime}$ and $7^{\prime}$. Similarly, the sequences between -11 and $-10.6 \mathrm{~kb}$ contribute both to stripe $7^{\prime}$ (Fig. 1) and to stripes 3 and 4 (Howard and Struhl 1990; Pankratz et al. 1990). Intermingling of

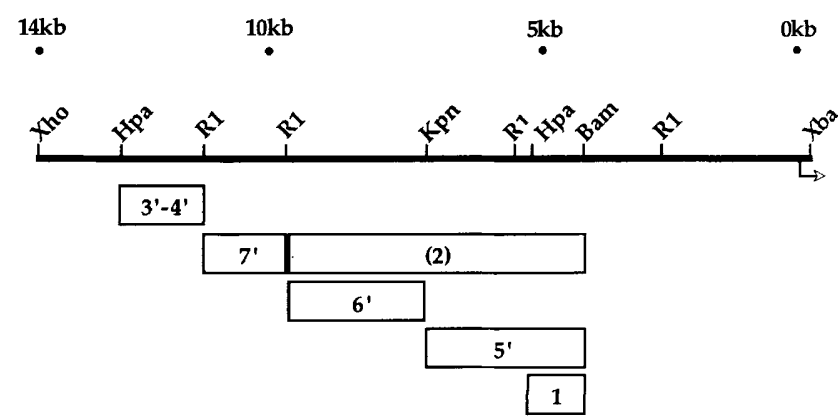

Figure 6. $h$ promoter sequences necessary and/or sufficient for the major lac $Z$ stripes. About $14 \mathrm{~kb}$ of $h$ promoter sequences is represented as a thick black line above which are shown selected restriction enzyme sites and distances from the start of transcription (denoted with an open arrow). The labeled open boxes below the promoter indicate sequences that are required for the lacZ stripes.

transcriptional control elements is not precluded and is often seen in eukaryotic promoters (e.g., $\mathrm{h} M T I I_{\mathrm{A}}$ and SV40; Serfling et al. 1985).

\section{Stripe phasing and regulation by pair-rule genes}

The refinement of pair-rule stripe phasing is vital for defining accurate segment-polarity expression domains. Several of our results suggest that upstream stripe elements defined in this study are inadequate to confer precise phase relationships. Stripe misphasing could be due to misregulation by the gap genes (see above) and/or by other pair-rule genes. The former possibility appears unlikely as several stripes are similarly affected; the latter is attractive because phasing interactions would then operate on most or all stripes.

The $f t z$ pair-rule response elements appear to lie within the 600-bp zebra element (Hiromi and Gehring 1987 , and it has been suggested that a discrete 800-bp element in the eve promoter responds directly to the primary pair-rule genes eve, $h$, and run (Goto et al. 1989).

Figure 5. Expression of $l a c Z$ stripes in zygotic gap and pair-rule gene mutant embryos. Mutant embryos were identified by their patterns of $h$ staining. (a) $\beta h 34$ expression in $K r$ homozygous embryos; a thin central stripe of lac $Z$ expression remains. $(b) \beta h 34$ expression in kni embryos; the domain is expanded posteriorly. (c) $\beta h K 567$ expression in kni embryos; lacZ expression spans the stripe 7 remnant (dark brown double-stained nuclei) and the $6 / 7$ interstripe region (anterior blue-staining cells). (d) $\beta h 6.5 \mathrm{~kb}$ expression in $K r$ embryos; here the lacZ is visualized using an X-gal histochemical stain (turquoise), and mutant embryos are identified by their $f t z$-staining pattern (brown). Stripe 1 is unaffected, but stripe $5^{\prime}$ is lost. (e) $\beta h 1(2) 5$ expression in $g t$ embryos; stripe 1 is unaffected, whereas stripe $5^{\prime}$ is expanded toward the posterior (underlined). $(f) \beta h 6.5 \mathrm{~kb}$ expression in $\mathrm{kni}$ embryos; stripe 1 is unaffected, whereas stripe $5^{\prime}$ is reduced to a very thin stripe (arrow). $(g) \beta h(2) 6$ expression in $K r$ embryos; these embryos are single-stained with anti-lac $Z$ antibody visualized immunohistochemically with an alkaline phosphatase second antibody. Stripe $6^{\prime}$ is expanded toward the anterior, and the weak stripe 2 is slightly expanded toward the posterior. $(h) \beta h(2) 6$ expression in $t l l$ embryos; stripe $6^{\prime}$ is expanded toward the posterior (underlined). Note the shifted anterior boundary and the repression of expression at the posterior pole. (i) $\beta h 7.2$ expression in kni embryos; the normally weak stripe $7^{\prime}$ is much stronger and expanded toward the anterior. (j) Expression of an enhancer trap transposon inserted into the $h$ locus, $P\left(l a c, r y^{+}\right) h^{L 43 a}$, was compared to the endogenous $h$ protein expression pattern. All $h$-expressing nuclei except those in the $\mathrm{AD}$ domain (brown) also express $l a c Z$ and appear dark gray-brown. (k) $\beta$ h1(2) 5 expression in run embryos; stripe 1 is expanded, and stripe $5^{\prime}$ is thinner. (1) A detail of a $\beta h 7.1$ transformant embryo (stained as in Fig. 2p) showing the posterior shift of stripe $7^{\prime} .(\mathrm{m})$ Antibody double staining with anti-lac $Z$ and anti-eve reveals coincidence of $1 a c Z 7^{\prime}$ with eve stripe 7 (detail). $|n|$ $\beta h 7.1$ expression in eve embryos; the level of stripe $7^{\prime}$ expression is unaffected, and it is still misphased relative to $h$ stripe 7 . (o) $\beta h(2) 6$ expression in a run embryo; stripe $6^{\prime}$ is expanded toward the posterior (underlined). 
However, the same fragment mediates eve autoregulation (Harding et al. 1989), so direct interactions with $h$ and run cannot be distinguished from indirect effects via eve. Such uncertainties do not apply to $h$, which is not autoregulated (Hooper et al. 1989). Our longest construct $(\beta h 14 k b)$ is the only one for which we see accurate phasing for all of the stripes. It includes the endogenous start of $h$ transcription and leader sequences, suggesting that they may harbor phasing elements. Several gene fusion constructs using the $h b$ promoter have suggested that pair-rule sequences downstream of the start of transcription can regulate interstripe expression (Parkhurst and Ish-Horowicz 1991).

Pair-rule cues may also act via dispersed upstream sequences. In particular, run affects $l a c Z$ stripes $1,5^{\prime}$, and $6^{\prime}[\beta h 1(2) 5$ and $\beta h(2) 6]$ similarly to their $h$ counterparts: Stripe 1 broadens posteriorly, stripe $5^{\prime}$ is weaker and thinner, and stripe $6^{\prime}$ is expanded posteriorly (Fig. $5 \mathrm{k}, \mathrm{o}$ ). These fragments do not overlap, suggesting that each stripe element includes its own run response element. If the run protein is a transcription factor, as suggested by its nuclear localization (Kania et al. 1990), it must act directly or indirectly through these elements.

\section{Stripe 1 regulation}

Stripe 1 is the only stripe that is accurately directed by a small promoter fragment (861 bp; Fig. $2 \mathrm{~g}-\mathrm{i}$ ). However, its regulation is still unclear. Only mutations that abolish or reduce $b c d$ concentrations cause loss of stripe $1: b c d$ and stau exu (Fig. 4; Ingham et al. 1985; Hooper et al. 1989). The stripe 1 element includes an excellent match to the consensus $b c d$-binding site (Rushlow et al. 1989), suggesting that $b c d$ might be acting directly. Stripe 1 is unaffected by otd mutations, the only other characterized gene with a related homeo box that might bind this site (Finkelstein et al. 1990).

If stripe 1 were regulated by $b c d$ alone, separate $b c d$ thresholds would define each stripe boundary. The first $h$ stripe is about five cells wide, over which $b c d$ protein concentration should differ by $\sim 15 \%$ (Driever and Nüsslein-Volhard 1988). However, the stripe is only slightly broadened in vas exu embryos where the gradient of $b c d$ is much shallower, indicating that although $b c d$ is required for the activation of stripe 1 , it alone does not define the stripe 1 domain.

Consistent with a previous study of $h$ protein expression, no individual gap gene abolishes stripe 1 expression (Hooper et al. 1989). This may reflect coordinate regulation by multiple head genes; redundant effects of $b c d$ and $h b$ on gap gene expression have been described previously (Hülskamp et al. 1990). $h$ stripe 1 lies anterior to the cephalic furrow in the head, where patterning mechanisms may differ from those in the body trunk (Cohen and Jürgens 1990).

The terminal system is also important for stripe 1 expression. Stripe 1 is expanded anteriorally in tor and $t 11$ embryos, suggesting that $t 11$ determines the anterior edge of 1 as well as the posterior edge of stripe $6^{\prime}$. The posterior duplication of stripe 1 in vas exu embryos indicates that stripe 1 requires interactions between $b c d$ and the terminal system. Such embryos retain an anteriorly shifted stripe 1 and a faint duplicated posterior stripe, confirming the suggestion that their final cuticle phenotype is a mirror image duplication of head structures (Schüpbach and Wieschaus 1986).

The stripe 1 element also retains dorsoventral regulation. $t$ wist protein may repress ventral expression by direct DNA binding to this element.

\section{Gap genes as activators and repressors}

In principle, varying levels of the nine gap genes lotd, $e m s, b t d, h b, K r, g t, k n i, t l l, h k b)$ could generate sufficient spatial diversity to generate the striped patterns of pair-rule gene expression. Thus, $h$ and eve are still overtly striped in the absence of the other primary pairrule genes (Carroll and Vavra 1989).

Our evidence supports the view that gap gene proteins act as both positive and negative regulators of transcription, rather than pair-rule striping arising exclusively by interstripe repression (Carroll and Vavra 1989). The reporter gene constructs show that each stripe element must include its own activator site(s) that can activate a heterologous promoter. In general, gap genes activate stripes that lie centrally within their domains and repress those at their edges (Fig. 7). Several different transformant lines show restricted broadening of expression, as expected if such activation were regionalized and directed by the gap genes. Individual gap genes have distinct effects on different stripes consistent with alternative positive/negative transcriptional functions, for example, $K r$ mutations abolish stripe $3^{\prime}-4^{\prime}$ and stripe $5^{\prime}$ and expand stripe $6^{\prime}$; gt mutations expand stripe $5^{\prime}$ but abolish stripe $6^{\prime} ;$, kni mutations reduce stripe $5^{\prime}$, abolish stripe $6^{\prime}$, and expand stripe $7^{\prime}$ (Fig. 7). Positive and negative transcriptional regulation by the same factor has been described in a number of other systems (Shore and Nasmyth 1987; Karin 1990). Thus, the function of a gap protein as an activator or repressor may depend on interactions with other factors.

Nevertheless, we cannot exclude gap genes acting exclusively as repressors (Carroll and Vavra 1989). It is formally possible that each stripe element includes its own general activation site on which the gap genes act indirectly via cross repression or by modulation of generalized transcription factor activity. Such positive factors are implied by the patchy lac $Z$ expression of stripes $6^{\prime}$ and $7^{\prime}$ (Fig. 2o,q) in which individual cells are activated independently. Stochastic initiation of gene expression due to limiting transcriptional components has been seen previously in differentiating hepatocytes (van Roon et al. 1989). Expression is dependent on a limiting component, not the gap genes, as activation within the stripe domains is not graded as are gap gene proteins. Also, gap gene heterozygosity does not affect the level or heterogeneity of lac $Z$ expression of either $6^{\prime}$ or $7^{\prime}$ stripes.

Although $h$ is clearly striped by the gap genes, detailed biochemical and mutational analysis will now be needed to distinguish between their direct and indirect effects. It 


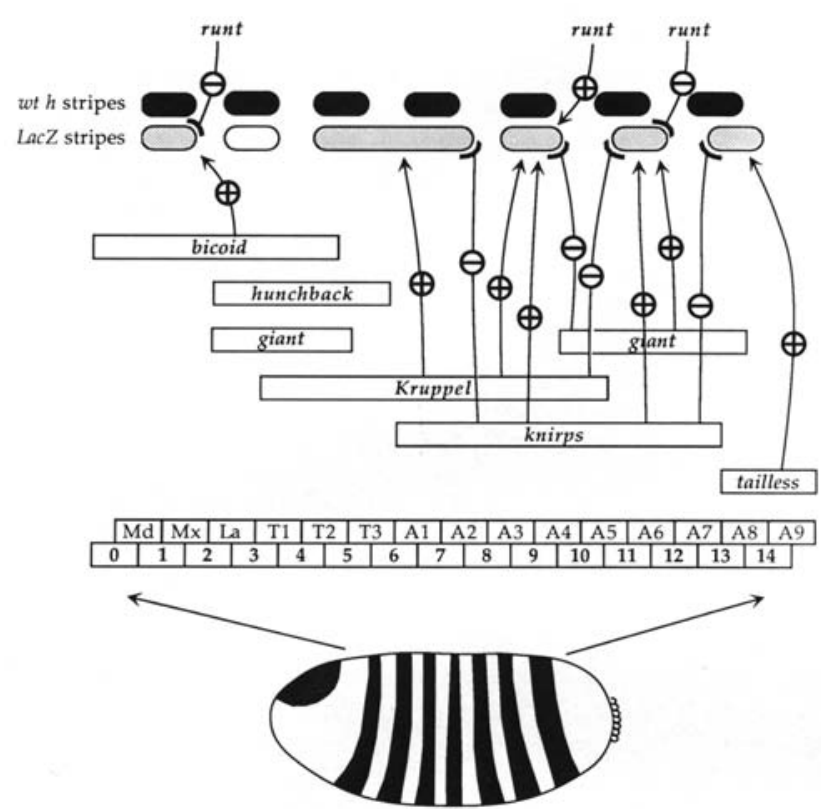

Figure 7. Interactions of the segmentation genes with the $1 a c Z$ stripe elements. The blastoderm stage expression pattern of $h$ is shown at the bottom. Directly above, the two bars represent the parasegmental (lower) and segmental (top) A/P fate map of the central, segmented portion of the blastoderm embryo. The domains of activity of $b c d$ and various gap genes, as determined by their effect on cuticle pattern, are shown as labeled open boxes aligned with the $\mathrm{A} / \mathrm{P}$ fate maps below. The interaction of these genes with the $l a c Z$ stripes is represented by either arrows (phenotypic activation) or bars (phenotypic repression) from the appropriate boxes to the appropriate stripes. Circled plus and minus signs reinforce the nature of the interaction. The $h$ /solid areas) domains and $l a c Z$ stripes (shaded areas, showing phasing relative to the wild-type $h$ stripes) are aligned above this. The effect of the pair-rule gene run on the lacZ stripes is shown at the top.

is unclear how gap genes activate a distant transcription start site, without interfering with adjacent or intervening stripe elements. Finally, we need molecular explanations for the sharp expression boundaries that allow pairrule genes to define the precise spatial domains of segment-polarity gene expression.

\section{Materials and methods}

\section{Plasmid constructions}

Most techniques employed in plasmid constructions are described in Sambrook et al. (1989). The lacZ fusion genes diagramed in Figure 1 were constructed in the following manner. The final vector $p \beta n 27.1$ is illustrated in Figure 8 and constructed as follows. pneo5 was generated by inserting the BgIII (filled in)-NdeI fragment containing the P-element ends and the hsp70-neomycin gene of pUChsneo (Steller and Pirrotta 1985) into pUC18 cut with HindIII (filled in) and NdeI. This manipulation introduces the pUC18 polylinker into pUChsneo and removes the small lacZ $\alpha$ fragment to avoid potential recombination with introduced $l a c Z$ reporter gene sequences.

The nuclear localization signal was introduced at the $l a c Z$ amino terminus in the following manner (S.M. Parkhurst, pers. comm.). The 3' BamHI site in pIRV-Neo-Act-lacZ (Beddington et al. 1989) was removed by partial digestion and Klenow DNA polymerase. Oligonucleotides N1 and N2,

$\begin{array}{lll}\text { N1 } & 5^{\prime} \text {-GATCCCACCCCCCCCAAGAAGAAGCGCAAGGTGGAGGAC } \\ \text { N2 } & 3^{\prime}-\quad \text { CGGTGGGGGGGGTTCTTCTTCGCGTTCCACCTCCTGCTAG } \cdot 5^{\prime}\end{array}$

were annealed and inserted into the remaining BamHI site to recreate only the 5'-most BamHI site, forming pIRV-5NT. This oligonucleotide encodes TPPKKKRKVED, the nuclear localization sequence of SV40 large T antigen (amino acids 124-134; Kalderon et al. 1984).

The nuclear tagged E. coli lacZ gene (HindIII-SalI) was cloned into pHSS7-Sal (T. Jowett, pers. comm.) introducing flanking BamHIII and SalI sites, and the hsp27 polyadenylation signal from hspXAS [BamHIII (blunted]-SalI; S. Parkhurst, pers. comm.) was inserted by using SnaBI and SalI, to form pnß3'. Oligonucleotides $\mathrm{K} 1$ and $\mathrm{K} 2$,

K1 5' AGCTGGATCCGCGGCCGCTACGTATCTAGACCACCATGGGA ${ }^{\prime} \mathbf{3}^{\prime}$ K2 $3^{\prime}$ CCTAGGCGCCGGCGATGCATAGATCTGGTGGTACCCTCTAG-5'

were inserted into $p \beta n 3^{\prime}$ cut with HindIII and BamHI, providing a eukaryotic ATG translation signal (Kosak 1986), a GGA (glycine), and a polylinker of BamHI, NotI, SnaBI, and XbaI, forming $p \beta n e o 1$. The BamHI-SaII fragment from $p \beta n e 01$ containing the nuclear $l a c Z$ was inserted into pneo5 to form pnlacZ1. The $X b a I$ fragment from $p C a t \Delta 1$, containing the $h s p 27$ TATA box and untranscribed RNA leader between -46 and +87 bp (Riddihough and Pelham 1986), was inserted into pnlacZ1, forming the final vector $p \beta n 27.1$. Orientation of the insert was determined by double-stranded sequencing. This plasmid contains

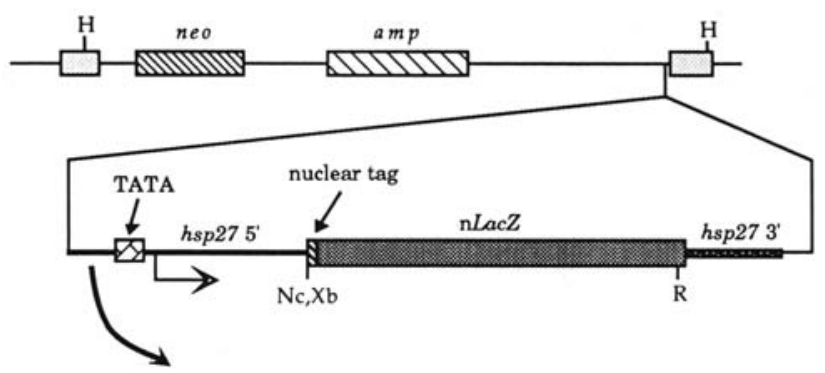

EcoR1,Sac1, Kpn1,Sma1,BamH1,Not1,SnaB1, Xba1

Figure 8. Structure of the P-element nuclear-lacZ expression vector, $p \beta n 27.1$. (Top) Sequences derived from $p U C h s n e o$ (Steller and Pirrotta 1985), including the P-element inverted repeats (lightly stippled boxes), the $\beta$-lacatamase gene ( $a m p)$, and heat shock neomycin gene (neo). The prokaryotic neo gene should not contain any fortuitous regulatory elements that might interfere with expression in Drosophila, unlike rosy (Doyle et al. 1989). The E. coli $\beta$-galactosidase gene (nlacZ; darkly stippled box) has an hsp27 TATA box, leader, and polyadenylation sequences. The in vivo start of transcription of hsp27 is indicated with an open arrow. A nuclear localization sequence, amino acids 124-134 of SV40 large T antigen, is fused to the amino terminus of the lacZ gene (S. Parkhurst, pers. comm.). A polylinker (below) facilitates cloning of foreign DNA upstream of the hsp27 TATA box (unique sites are in boldface type); otherwise, restriction enzyme sites are as in Fig. 1. The cloning site is internal to the construct to minimize the effects of flanking sequences in the genome. 
unique sites $5^{\prime}$ of the hsp27 TATA box for the following restriction enzymes: KpnI; SmaI; BamHI; NotI; SnaBI (Fig. 8), into which the $h$ fragments were inserted. Some $h$ promoter fragments were first inserted into Bluescript(M13 + |KS (Stratagene) to facilitate cloning; this led to inclusion of additional polylinker sequences.

\section{Germ-line transformation}

Flies were grown on yeast/maize meal/molasses/malt extract/ agar medium at room temperature or at $25^{\circ} \mathrm{C}$. Germ-line transformants were generated essentially as described by Steller and Pirrotta (1985), by using medium containing $1.2-1.6 \mathrm{mg} / \mathrm{ml}$ of G418 (Geneticin; GIBCO, titrated according to batch). Transformants were generated by DNA injection into $b w$; st embryos, selected while outcrossing to Oregon- $R$ on drug food, and mapped by backcrossing to $b w ; s t$ on drug food. Stocks were balanced with $F M 7, C y O$, or TM3 and maintained as homozygous $b w$ or st lines where possible. The number of transformant lines analyzed for each construct is shown in parenthesis: $\beta h 14 k b(1), \beta h 6.5 \mathrm{~kb}(3), \beta h 7 k b(2), \beta h 7 k b I N V(2), \beta h 0.3 I N V(2)$,

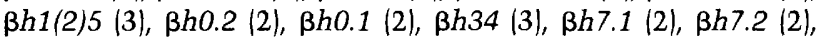
$\beta h R 567(3), \beta h(2) 6(2), \beta h(2) 6 I N V(2), \beta h K 567$ (2), and $\beta h 1.1$ (3).

\section{Analysis of $\mathrm{h}-\mathrm{lacZ}$ fusion expression in mutant backgrounds}

The maternal mutant alleles used were tor ${ }^{\text {WK34 }}$, osk ${ }^{166}$, nos $^{L 7}$, $b c d^{E 1}, \operatorname{nos}^{L 7}$, sta ${ }^{D 3}, e x u^{Q R}, v_{a s}{ }^{P D} e x u^{Q R}$, and $d l^{1}$. The zygotic gap gene mutant alleles used were otd ${ }^{Y H}, e m s^{7 D 99}$ and $e m s^{10 A 37}$, btd $d^{I I A}, h b^{P X T 15}, K r^{1}, k^{I I D 48}$ (Fig. 4c,f) and $k n i^{I I V 95}$ (Fig. 4b,i), $g t^{Y A}, t l l^{L 10}$, and $h k b^{2}$. The zygotic pair-rule gene mutants used were $e v e^{1.27}$ and run ${ }^{L B 5}$. For zygotic mutations, embryos were double-stained for $l a c Z$ and either $h$, eve, or $f t z$; homozygous mutant embryos were identified by their altered endogenous pair-rule patterns.

\section{Embryo staining}

Embryo collection, dechorionation, fixing (in $4 \%$ formaldehyde/PBS), and antibody staining were carried out according to standard procedures (Macdonald and Struhl 1986; Wieschaus and Nüsslein-Volhard 1986). Initial experiments used direct histochemical detection of lacZ (Ghysen and O'Kane 1989), but subsequent experiments used a rabbit polyclonal anti-lac $Z$ antibody (gift of Dr J. Seely, National Institute for Medical Research, London) and alkaline phosphatase-coupled secondary antibodies. For antibody double-staining, the embryos were incubated in a mixture of the appropriate primary antibodies (raised in different host species): mouse polyclonal anti- $h$ antibodies (S.M. Pinchin, unpubl.); rabbit anti-eve and anti-ftz antibodies (Frasch et al. 1987; Krause et al. 1988). The embryos were washed and incubated in a mixture of the appropriate secondary antibodies: $l a c Z$ as above; eve or $f t z$ used secondary antibody directly coupled to peroxidase (HRP); $h$ was detected with biotinylated secondary antibody and HRP-ABC complexes (Vectastain Elite kit). Final staining was conducted sequentially: first, diaminobenzidine reaction for HRP at $\mathrm{pH} 5.5$, followed by alkaline phosphatase at $\mathrm{pH} 9.5$ using bromochloroindolyl phosphate and nitro-blue tetrazolium substrates (BRL). All secondary antibodies were obtained from Jackson Laboratories.

lacZ transcripts were detected by using whole-mount digoxigenin (DIG) in situ hybridization essentially as described in Tautz and Pfeifle (1989) except that probe synthesis was carried out at $14^{\circ} \mathrm{C}$ (B. Edgar, pers. comm.). The lac $Z$ probe was the $3-\mathrm{kb}$ $E c o$ RI-XbaI fragment from $p \beta n 27.1$ (Fig. 8). Stripe identities were inferred from their positions, which were determined by measuring percent egg length with an eyepiece graticule.

Following staining for protein or RNA, embryos were washed, rinsed briefly in $95 \%$ ethanol, and mounted in methacrylate (JB-4; Polysciences). All embryos were photographed under Nomarski optics on Fujichrome 64T (color positive) or Kodak Technical Pan $(b / w)$ film. The color slide images were printed on Cibachrome-AII paper using the Ilford Cibachrome-A P-30 process.

\section{Acknowledgments}

We acknowledge Sheena Pinchin for making the $h$ polyclonal antibodies used in this study; Susan Parkhurst for teaching germ-line transformation to G.R., generously providing the nuclear tagged lac $Z$ gene, and her constant encouragement and advice; Ilan Davis for help with DIG whole-mount RNA in situs and for the in situ shown in Figure $2 a$; Michael Lardelli for many discussions and communication of unpublished data; Ken Howard for communication of unpublished data; Christiane Nüsslein-Volhard for providing various fly stocks; Peter Nash and Sue Matheson for media facilities; and Catherine Bramwell for help in maintaining fly stocks at moments of crisis. We thank Michael Lardelli, Bruce Edgar, Susan Parkhurst, and Ze'ev Paroush for critical appraisal of the manuscript. A special mention must go to Susan Parkhurst for her maintenance of lab morale through numerous superbly cooked foods.

The publication costs of this article were defrayed in part by payment of page charges. This article must therefore be hereby marked "advertisement" in accordance with 18 USC section 1734 solely to indicate this fact.

\section{References}

Beddington, R.S., J. Morgernstern, H. Land, and A. Hogan. 1989. An in situ transgenic enzyme marker for the midgestation mouse embryo and the visualization of inner cell mass clone during early organogenesis. Development 106: 37-46.

Carroll, S.B. and S.H. Vavra. 1989. The zygotic control of Drosophila pair-rule gene expression. II. Spatial repression by gap and pair-rule gene products. Development 107: 673-683.

Carroll, S.B., S. DiNardo, P.H. O'Farrell, R.A.H. White, and M.P. Scott. 1988a. Temporal and spatial relationships between segmentation and homeotic gene expression in Drosophila embryos: Distributions of the fushi tarazu, engrailed, Sex combs reduced, Antennapedia, and Ultrabithorax. Genes \& Dev. 2: 350-360.

Carroll, S.B., A. Laughon, and B.S. Thalley. 1988b. Expression, function and regulation of the hairy segmentation protein in the Drosophila embryo. Genes \& Dev. 2: 883-890.

Casanova, J. 1990. Pattern formation under the control of the terminal system in the Drosophila embryo. Development 110: $621-628$.

Cohen, S.M. and G. Jürgens. 1990. Mediation of Drosophila head development by gap-like segmentation genes. Nature 346: 482-484.

Dearolf, C.R., J. Topol, and C.S. Parker. 1989. Transcriptional control of Drosophila fushi tarazu zebra stripe expression. Genes \& Dev. 3: 384-398.

Doyle, H.J., R. Kraut, and M. Levine. 1989. Spatial regulation of zerknüllt-A dorsal-ventral patterning gene in Drosophila. Genes \& Dev. 3: 1518-1533.

Driever, W. and C. Nüsslein-Volhard. 1988. A gradient of bicoid protein in Drosophila embryos. Cell 54: 83-93.

Driever, W., G. Thoma, and C. Nüsslein-Volhard. 1989. Deter- 
mination of spatial domains of zygotic gene expression in the Drosophila embryo by the affinity of binding sites for the bicoid morphogen. Nature 340: 363-367.

Edgar, B.A., G.M. Odell, and G. Schubiger. 1987. Cytoarchitecture and the patterning of fushi tarazu expression in the Drosophila blastoderm. Genes \& Dev. 1: 1126-1247.

Fasano, L., N. Coré, and S. Kerridge. 1988. Expression of a reporter gene resembles that of its neighbour: An insertion in the hairy gene of Drosophila. Roux's Arch. Dev. Biol. 197: 507-512.

Finkelstein, R., D. Smouse, T.M. Capaci, A.C. Spradling, and N. Perrimon. 1990. The orthodenticle gene encodes a novel homeo domain protein involved in the development of the Drosophila nervous system and ocellar visual structures. Genes \& Dev. 4: 1516-1527.

Frasch, M. and M. Levine. 1987. Complementary patterns of even-skipped and fushi tarazu expression involve their differential regulation by a common set of segmentation genes in Drosophila. Genes \& Dev. 1: 981-995.

Frasch, M., T. Hoey, C. Rushlow, H. Doyle, and M. Levine. 1987. Characterization and localization of the even-skipped protein of Drosophila. EMBO I. 6: 749-759.

Frasch, M., R. Warrior, J. Tugwood, and M. Levine. 1988. Molecular analysis of even-skipped mutants in Drosophila development. Genes \& Dev. 2: 1824-1838.

Frohnhöfer, H.G. and C. Nüsslein-Volhard. 1986. Organization of anterior pattern in the Drosophila embryo by the maternal gene bicoid. Nature 324: 120-125.

Gaul, U. and H. Jäckle. 1989. Analysis of maternal effect mutant combinations elucidates regulation and function of the overlap of hunchback Krüppel gene expression in the Drosophila blastoderm embryo. Development 107: 651-662.

Gaul, U., E. Seifert, R. Schuh, and H. Jäckle. 1987. Analysis of Krüppel protein distribution during early Drosophila development reveals post-transcriptional regulation. Cell 50: 639-647.

Ghysen, A. and C. O'Kane. 1989. Neural enhancer-like elements as specific cell markers in Drosophila. Development 105: 35-52.

Goto, T., P.M. Macdonald, and T. Maniatis. 1989. Early and late periodic patterns of even-skipped expression are controlled by distinct regulatory elements that respond to different spatial cues. Cell 57: 413-422.

Harding, K., T. Hoey, R. Warrior, and M. Levine. 1989. Autoregulatory and gap gene response elements of the evenskipped promoter of Drosophila. EMBO J. 8: 1205-1212.

Hiromi, Y. and W.J. Gehring. 1987. Regulation and function of the Drosophila segmentation gene fushi tarazu. Cell 50: $963-974$.

Hiromi, Y., A. Kuroiwa, and W.J. Gehring. 1985. Control elements of the Drosophila segmentation gene fushi tarazu. Cell 43: 603-613.

Hooper, K.L.H., S.M. Parkhurst, and D. Ish-Horowicz. 1989. Spatial control of hairy protein expression during embryogenesis. Development 107: 489-504.

Howard, K.R. 1990. The blastoderm pattern. Pattern formation in Drosophila. Sem. Cell Biol. 1: 161-172.

Howard, K.R. and G. Struhl. 1990. Decoding positional information: Regulation of the pair-rule gene hairy. Development 110: 1223-1231.

Howard, K., P. Ingham, and C. Rushlow. 1988. Region-specific alleles of the Drosophila segmentation gene hairy. Genes \& Dev. 2: 1037-1046.

Hülskamp, M., C. Pfeifle, and D. Tautz. 1990. A morphogenetic gradient of hunchback protein organizes the expression of the gap genes Krüppel and knirps in the early Drosophila embryo. Nature 346: 577-580.

Ingham, P.W. 1988. The molecular genetics of embryonic pattern formation in Drosophila. Nature 335: 25-34.

Ingham, P.W. and J.P. Gergen. 1988. Interactions between the pair-rule genes runt, hairy, even-skipped and fushi tarazu and the establishment of periodic pattern in the Drosophila embryo. Mechanisms of segmentation. Development (suppl.) 104: 51-60.

Ingham, P.W., K.R. Howard, and D. Ish-Horowicz. 1985. Transcription pattern of the Drosophila segmentation gene hairy. Nature 318: 439-445.

Ingham, P.W., N.E. Baker, and A. Martinez-Arias. 1988. Regulation of segment polarity genes in the Drosophila blastoderm by fushi tarazu and even-skipped. Nature 331: 73-75.

Ish-Horowicz, D., K.R. Howard, S.M. Pinchin, and P.W. Ingham. 1985. Molecular and genetic analysis of the hairy locus in Drosophila. Cold Spring Harbor Symp. Quant. Biol. 50: $135-144$.

Ish-Horowicz, D., S.M. Pinchin, P.W. Ingham, and H.G. Gyurkovics. 1989. Autocatalytic $f t z$ activation and metameric instability induced by ectopic $f t z$ expression. Cell 57: 223-232.

Jaynes, J.B. and P.H. O'Farrell. 1988. Activation and repression of transcription by homeodomain-containing proteins that bind a common site. Nature 336: 744-749.

Kalderon, D., B.L. Roberts, W.D. Richardson, and A.E. Smith. 1984. A short amino acid sequence able to specify nuclear location. Cell 39: 499-509.

Kania, M.A., A.S. Bonner, J.B. Duffy, and J.P. Gergen. 1990. The Drosophila segmentation gene runt encodes a novel nuclear regulatory protein that is also expressed in the developing nervous system. Genes \& Dev. 4: 1701-1713.

Karin, M. 1990. Too many transcription factors: Positive and negative interactions. New Biologist 2: 126-131.

Kosak, M. 1986. Point mutations define a sequence flanking the AUG initiator codon that modulates translation by eukaryotic ribosomes. Cell 44: 283-292.

Krause, H.M., R. Klemenz, and W.J. Gehring. 1988. Expression, modification and localization of the fushi tarazu protein in Drosophila embryos. Genes \& Dev. 2: 1021-1036.

Lehmann, R. and H.J.G. Frohnhöfer. 1989. Segmental polarity and identity in the abdomen of Drosophila is controlled by the relative position of gap gene expression. The molecular basis of positional signalling. Development (suppl.) 107: 2129.

Macdonald, P.M. and G. Struhl. 1986. A molecular gradient in early Drosophila embryos and its role in specifying body pattern. Nature 324: 537-545.

Nüsslein-Volhard, C. and E. Wieschaus. 1980. Mutations affecting segment number and polarity in Drosophila. Nature 287: 795-801.

Nüsslein-Volhard, C., H.G. Frohnhöfer, and R. Lehmann. 1987. Determination of anteroposterior polarity in Drosophila. Science 238: 1675-1681.

O'Kane, C.J. and W.J. Gehring. 1987. Detection in situ of genomic regulatory elements in Drosophila. Proc. Natl. Acad. Sci. 84: 9123-9127.

Pankratz, M.J. and H. Jäckle. 1990. Making stripes in the Drosophila embryo. Trends Genet. Sci. 6: 287-292.

Pankratz, M.J., M. Hoch, E. Seifert, and H. Jäckle. 1989. Krüppel requirement for knirps enhancement reflects overlapping gap gene activities in the Drosophila embryo. Nature 341: $337-340$.

Pankratz, M.J., E. Seifert, N. Gerwin, B. Billi, U. Nauber, and H. Jäckle. 1990. Gradients of Krüppel and knirps gene products direct pair-rule gene stripe patterning in the posterior region of the Drosophila embryo. Cell 61: 309-317. 
Parkhurst, S.M. and D. Ish-Horowicz. 1991. Misregulating segmentation gene expression in Drosophila. Development (in press).

Riddihough, G. and H.R.B. Pelham. 1986. Activation of the Drosophila hsp 27 promoter by heat shock and by ecdysone involves independent and remote regulatory sequences. EMBO J. 7: 1653-1658.

Rushlow, C.A., A. Hogan, S.M. Pinchin, K.R. Howe, M.T. Lardelli, and D. Ish-Horowicz. 1989. The Drosophila hairy protein acts in both segmentation and bristle patterning and shows homology to N-myc. EMBO J. 8: 3095-3103.

Sambrook, J., E.F. Fritsch, and T. Maniatis. 1989. Molecular cloning: A laboratory manual. Cold Spring Harbor Laboratory Press, Cold Spring Harbor, New York.

Schüle, R., M. Muller, H. Otsuka-Murakami, and R. Renkawitz. 1988. Cooperativity of the glucocorticoid receptor and the CACCC-box binding factor. Nature 332: 87-90.

Schüpbach, T. and E. Wieschaus. 1986. Maternal-effect mutations altering the anterior-posterior pattern of the Drosophila embryo. Wilhelm Roux's Archiv. Dev. Biol. 195: 302317.

Serfling, E., M. Jasin, and W. Schaffner. 1985. Enhancers and eukaryotic gene transcription. Trends Genet. Sci. 1:224230.

Shore, D. and K. Nasmyth. 1987. Purification and cloning of a DNA binding protein from yeast that binds to both silencer and activator elements. Cell 51: 721-732.

Stanojevic, D., T. Hoey, and M. Levine. 1989. Sequence specific DNA-binding activities of the gap proteins encoded by hunchback and Krüppel in Drosophila. Nature 341:331335.

Steller, H. and V. Pirrotta. 1985. A transposable $\mathrm{P}$ vector that confers G418 resistance to Drosophila larvae. EMBO $J$. 4: $167-171$.

Struhl, G. 1989. Morphogen gradients and the control of body pattern in insect embryos. Cellular basis of morphogenesis. Ciba Found. Symp. 144: 65-91.

Struhl, G., K. Struhl, and P. M. Macdonald. 1989. The gradient morphogen bicoid is a concentration-dependent transcriptional activator. Cell 57: 1259-1273.

Tautz, D. and C. Pfeifle. 1989. A non-radioactive in situ hybridization method for the localization of specific RNAs in Drosophila embryos reveals translational control of the segmentation gene hunchback. Chromosoma (Berl) 98: 81-85.

Thisse, B., C. Stoetzel, C. Gorostiza-Thisse, and F. PerrinSchmitt. 1988. Sequence of the twist gene and nuclear localization of its protein in endomesodermal cells of early Drosophila embryos. EMBO I. 7: 2175-2183.

Topol, J., D. Ruden, and C.S. Parker. 1985. Sequences required for in vitro transcriptional activation of a Drosophila hsp 70 gene. Cell 42: 527-537.

van Roon, M.A., J.A. Atne, C.H. van Oven, R. Charles, and W.H. Lamers. 1989. The initiation of hepatocyte specific gene expression within embryonic hepatocytes is a stochastic event. Dev. Biol. 136: 508-516.

Wieschaus, E. and C. Nüsslein-Volhard. 1986. Looking at embryos. In Drosophila, a practical approach (ed. D.B. Roberts), pp. 199-226. IRL Press, Oxford. 


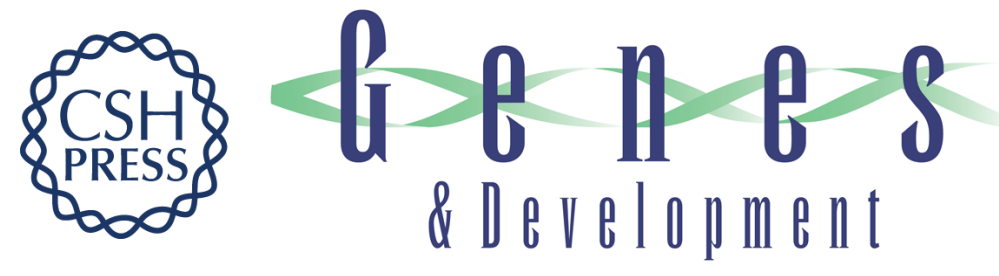

\section{Individual stripe regulatory elements in the Drosophila hairy promoter respond to maternal, gap, and pair-rule genes.}

G Riddihough and D Ish-Horowicz

Genes Dev. 1991, 5:

Access the most recent version at doi:10.1101/gad.5.5.840

References This article cites 63 articles, 22 of which can be accessed free at: http://genesdev.cshlp.org/content/5/5/840.full.html\#ref-list-1

License

Email Alerting

Service

Receive free email alerts when new articles cite this article - sign up in the box at the top right corner of the article or click here.

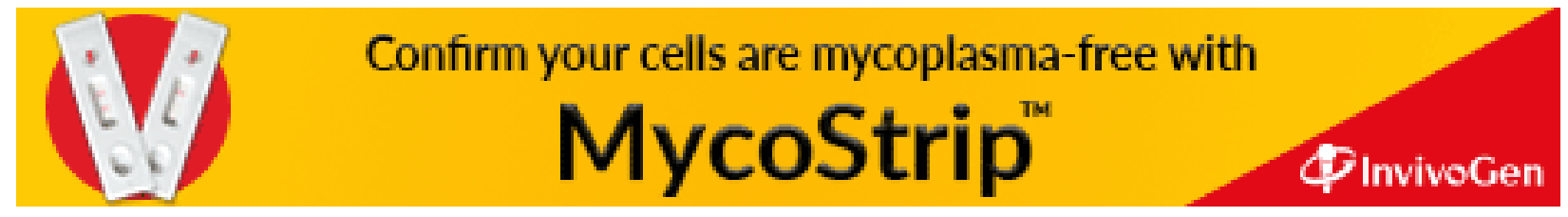

